\title{
New Method of Generation of Carbon Molecules and Clusters
}

\author{
Alexey Kharlamov', Ganna Kharlamova ${ }^{2}$, Marina Bondarenko ${ }^{1 *}$, Veniamin Fomenko $^{1}$ \\ ${ }^{1}$ Frantsevich Institute for Problems of Materials Science of NASU, Kiev, Ukraine \\ ${ }^{2}$ Taras Shevchenko National University of Kiev, Kiev, Ukraine \\ Email: *dep73@ipms.kiev.ua, mebondarenko@ukr.net
}

Received November 26, 2012; revised December 25, 2012; accepted January 6, 2013

\begin{abstract}
Firstly the method of joint synthesis of carbon molecules and their hydrides is developed. The stage of high-temperature sublimation of carbon in a new method of generation of carbon molecules is completely excluded. By mass spectrometric method the condensation products of new method of pyrolysis (NMP) benzene are studied. Firstly clusters $\left(\mathrm{C}_{3}-\mathrm{C}_{17}\right)$, typical for carbon vapour, in substances obtained under pyrolysis of hydrocarbons were detected. Fullerene $\mathrm{C}_{60}$ and its hydrides, quasi-fullerenes $\mathrm{C}_{48}$ and $\mathrm{C}_{33}$ in products of benzene pyrolysis are detected also. Firstly it is shown what clusters $\mathrm{C}_{3}-\mathrm{C}_{5}$ can be generated at so low $\left(100^{\circ} \mathrm{C}-200^{\circ} \mathrm{C}\right)$ temperatures of decomposition of substance. Obtained experimental results firstly demonstrate that the small carbon molecules can be generated in reactionary conditions excluding evaporation of carbon. Dehydrogenation and destruction of hydrocarbon molecules is the first stage on a route of the transformation of benzene to carbon molecules.
\end{abstract}

Keywords: Pyrolysis; Benzene; Fullerene; Quasi-Fullerene; Small Molecules; Mass Spectra; Carbon Clusters

\section{Introduction}

It is considered, that precursor of formation of carbon molecules are carbon clusters, generated at high-temperature evaporation processes of carbon or materials on its basis. One year early to discovery of fullerene $\mathrm{C}_{60}$ by Kroto et al. [1], Rofling [2] obtained the unique mass spectrum of carbon clusters that were created at laser evaporation of graphite in a flow of inert gas. In mass spectrum alongside with even and odd carbon clusters of the small sizes $C_{n}(1<n<30)$ were detected even clusters $C_{n}(n>30)$, including clusters, appropriate to fullerenes opened later. Kroto et al. [1] have created the special conditions of increased collision (clusterization) of carbon clusters and firstly have obtained mass spectrum of carbon vapour, which contained mainly clusters $\mathrm{C}_{60}$ and $\mathrm{C}_{70}$. Isolation of many others clusters, observable in Rofling mass spectrum [2], from carbon vapour has appeared immeasurably more difficult task. Only after 6 years (in 1990) after detection of fullerenes $C_{60}$ and $C_{70}$ by mass spectrometric method, Kretchemer [3] succeeded to create conditions of the arc-discharge, which have allowed to fulfill not only the clusterization of generated carbon vapour with primary formation of $\mathrm{C}_{60}$ and $\mathrm{C}_{70}$, but also to locate them in appreciable amounts in obtained fullerene soot. The research by mass spectro-

${ }^{*}$ Corresponding author. metric method of a powder [3], obtained at evaporation of benzene extract from fullerene soot, has shown presence of positive ions with $\mathrm{m} / \mathrm{z} 60$ and 70 in the ratio $10: 1$ in mass spectrum.

The further researches of benzene extracts from fullerene soot have shown [4] that in carbon vapour generated by the arc-discharge method can be realized raising clusterization with the formation of larger than $\mathrm{C}_{60}$ and $\mathrm{C}_{70}$ molecules. It was possible to allocate fullerenes $\mathrm{C}_{76}, \mathrm{C}_{84}$, $\mathrm{C}_{86}, \mathrm{C}_{90}$ and $\mathrm{C}_{94}$ [5], and also $\mathrm{C}_{78}$ [6] from o-xylene (or $o$-dichlorobenzene) extracts of fullerene soot by a chromatography method $\left(\mathrm{Al}_{2} \mathrm{O}_{3}\right.$, toluene). However some of "high" fullerenes such as $\mathrm{C}_{74}$ and $\mathrm{C}_{80}$ is not possible to isolate because of extremely high propensity of the given molecules with not coupled electrons [7] to polymerization.

In [8] carbon clusters, earlier detected only in carbon plasma, were found out in gases of a flame of incomplete combustion of benzene by means of mass spectrometric method. This method has appeared most effective for obtaining of fullerenes [9]. Presence of $\mathrm{C}_{60}$ and $\mathrm{C}_{70}$ is found out also in mass spectra of products of heat treatment of benzene and acetylene [10], naphthalene $\mathrm{C}_{10} \mathrm{H}_{6}$ and corannulene [11-13].

Thus, from large amount clusters generated at super high temperatures of the evaporations and burning of carbon and benzene accordingly are synthesized only 
fullerene $\mathrm{C}_{60}$ and its homologues as more stable molecules with isolated pentagons. Only $\mathrm{C}_{36}$ was synthesized from smaller carbon molecules with adjacent pentagons, quasi-fullerenes [14]. (Though in [15] there is information about obtaining by an arc-discharge method hydrides $\left(\mathrm{C}_{36} \mathrm{H}_{4}, \mathrm{C}_{36} \mathrm{H}\right)$ and oxy-hydrides $\left(\mathrm{C}_{36} \mathrm{H}_{4} \mathrm{O}, \mathrm{C}_{36} \mathrm{H}_{6} \mathrm{O}\right)$ only, but not molecules $\mathrm{C}_{36}$ ). Unsuccessful attempts to synthesize quasi-fullerenes are explained by their low stability because of presence of adjacent pentagons at the structure. However quasi-fullerene $\mathrm{C}_{20}$, which molecule consists of only pentagons, is easily formed at an irradiation of polythene by a beam of ions $\mathrm{Ar}^{+}$[16] and laser ablation of diamond [17]. On the other hand, quasifullerenes $\mathrm{C}_{28}$ and $\mathrm{C}_{50}$ with smaller number of adjacent pentagons are formed only as their derivative: endofullerene $\mathrm{M} @ \mathrm{C}_{28}(\mathrm{M}-\mathrm{Ti}, \mathrm{Zr}$, Hf or U) [18] and decahlorofullerene $\mathrm{C}_{50} \mathrm{Cl}_{10}$ [19].

As to ions of small clusters $C_{n}(n<20)$, which always present in carbon plasma [2] and flame of a benzene/ oxygen stream $[8,9]$, the molecules, appropriate to them, for example $\mathrm{C}_{2}$ and $\mathrm{C}_{3}, \mathrm{C}_{4}$ and $\mathrm{C}_{5}$ are found out only in circumstellar medium [20]. From carbon vapour the chains $\mathrm{C}_{1}-\mathrm{C}_{10}$ stabilize in solutions of methanol or acetonitrile due to a connection to trailer atoms of carbon $\mathrm{H}, \mathrm{N}$ or $\mathrm{CN}$ with formation of relatively more stable polyynes [21] or cyanopolyynes [22]. The technology of matrix isolation of carbon vapour in solid argon (or neon) at 25 - $14 \mathrm{~K} \mathrm{[23]} \mathrm{allows} \mathrm{to} \mathrm{keep} \mathrm{carbon} \mathrm{chains,} \mathrm{but} \mathrm{time}$ of life of such frozen clusters is extremely small $(\sim 10 \mathrm{~ms})$ [24].

The results of study by a mass spectroscopic method of the condensed products of a new method of pyrolysis (NMP) of benzene are presented and discussed in the report. Firstly in mass spectra of several solid products of condensation as and in carbon plasma (or in flame gases) small carbon clusters, new carbon molecules (quasi-fullerenes) as well as fullerene $\mathrm{C}_{60}$ and it hydrides are detected simultaneously. The stage of high-temperature sublimation of carbon in a new method of generation of carbon molecules of the different size is completely excluded.

\section{Experimental Results and Discussion}

Earlier [25-28] we have been systematically studied the influence of various technological parameters on composition of obtained products and, in particular, condensed substances formed at heat treatment of hydrocarbons. On the basis of the experimental results the new method of pyrolysis (NMP) of organic vapours was developed [28-31]. This method differs from two already known processes of pyrolysis [32]. Flash-pyrolysis (FP) [32,33] is used for obtaining of highly active objects of very small size. Flowing continuous pyrolysis (FCP) [32,34] is applied to obtain carbon nanostructures and polyaro- matic hydrocarbons (PAH). NMP allows obtaining simultaneously not only carbon nanostructures but also practically all carbon clusters detected in carbon plasma. Distinctive feature of NMP is an opportunity of partial division of products deposition and condensation. The time of stay of reagents in the most high temperature $\left(\sim 1000^{\circ} \mathrm{C}\right)$ zone $\mathbf{A}$ of reaction can be changed in a wide interval that allows generating of intermediate products. A part of condensed substances and pyrolytic soot are taken out from a zone $\mathbf{A}$ and are located in more lowtemperature zones $\mathbf{B}$ and $\mathbf{D}$. Vapour-like products (sometimes together with traces of soot) also is condensed in the special zone $\mathbf{C}$ of cooled reactionary space. Products of several $(8$ - 10) experiences obtained at given temperature taken from zones $\mathbf{B}, \mathbf{C}$ and $\mathbf{D}$ were blended. Results of study of the condensed products $\mathbf{B}, \mathbf{C}$ and $\mathbf{D}$ of the heat treatment of benzene vapours by a method of matrix-assisted laser (nitrogen, $337 \mathrm{~nm}$ ) desorption/ionization (MALDI) (Bruker Daltonics Flex Analysis) are submitted here. The extract (ethanol, toluene or water) was located on a metal substrate and after evaporation of the solvent was exposed to a laser irradiation.

\subsection{Products of Zone B}

From a product, located in a zone $\mathbf{B}$, condensed substances were extracted serially by toluene $\mathbf{B}_{1}$ and then ethanol $\mathbf{B}_{\mathbf{2}}$. After evaporation of ethanol from a solution $\mathbf{B}_{\mathbf{2}}$ a deposit $\mathbf{B}_{\mathbf{3}}$ have obtained as conglomerates from transparent white crystals. The deposit $\mathbf{B}_{\mathbf{3}}$ is easily dissolved in water $\mathbf{B}_{\mathbf{4}}$. In mass spectrum of negative ions of a water solution $\mathbf{B}_{\mathbf{4}}$ (Figure 1) there are peaks which correspond to values $\mathrm{m} / \mathrm{z}(48,60,72,84,96,108,120$ and 132) differing precisely on 12 units (Figure 1, inset). The similar periodicity is connected to different number of atoms of carbon in detected clusters: $\mathrm{C}_{4}, \mathrm{C}_{5}, \mathrm{C}_{6}, \mathrm{C}_{7}, \mathrm{C}_{8}$, $\mathrm{C}_{9}, \mathrm{C}_{10}$ and $\mathrm{C}_{11}$. The spectrum of cations contains some peaks of small intensity with m/z: 429 and 219 .

Mass spectra of cations and anions of a sample $\mathbf{B}_{\mathbf{2}}$ contain two general peaks with $\mathrm{m} / \mathrm{z} 72$ (cluster $\mathrm{C}_{6}$ ) and $\mathrm{m} / \mathrm{z} 144$ (cluster $\mathrm{C}_{12}$ ). In mass spectrum of anions (Figure 2 ) the periodicity already marked for $\mathbf{B}_{4}$ is observed among the most intensive peaks: 8 clusters with consecutive (in 12 units) increasing of number of carbon atoms from $\mathrm{C}_{3}$ up to $\mathrm{C}_{14}$ (Figure 2, inset). Also peaks with $\mathrm{m} / \mathrm{z}$ 219 and 429 are contained in a spectrum of cations, those were found out in a spectrum of a product $\mathbf{B}_{\mathbf{4}}$. Therefore it is possible to assume that in ethanol and water the substance (or substances) is dissolved which is exposed to destruction with formation of small carbon clusters from $\mathrm{C}_{3}$ up to $\mathrm{C}_{12}$ under action of a laser beam. Though, probably that separate small carbon molecules are stabilized in ethanol and in water as well. Earlier a similar range of carbon clusters was detected only in carbon plasma [2], in gases of benzene combustion [9] and at a 


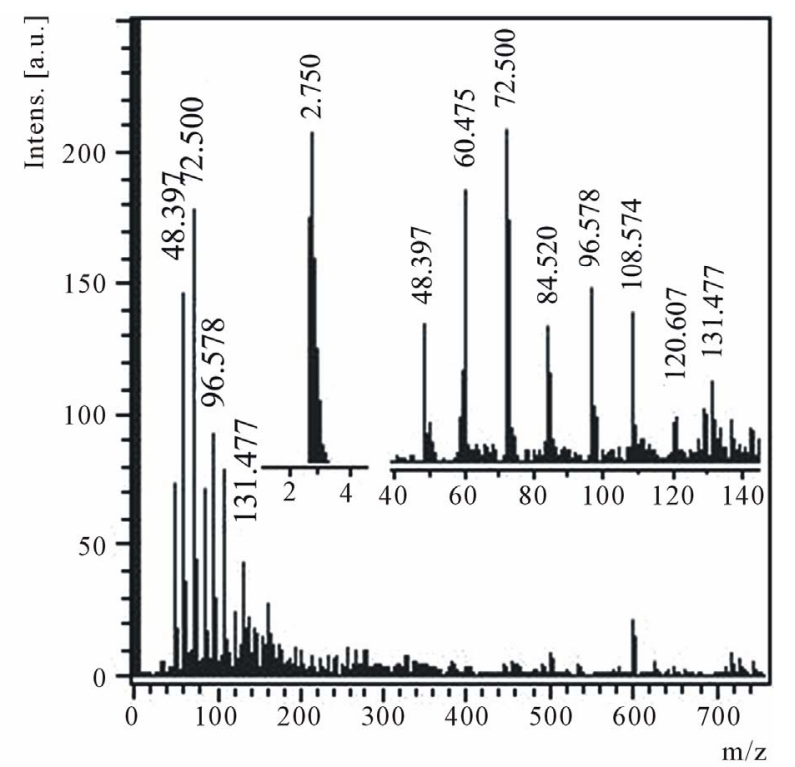

Figure 1. Anions mass spectrum of a water solution of the product $B_{4}$ with $\mathrm{m} / \mathrm{z} 40-150$ and $2-4$ regions in the insets.

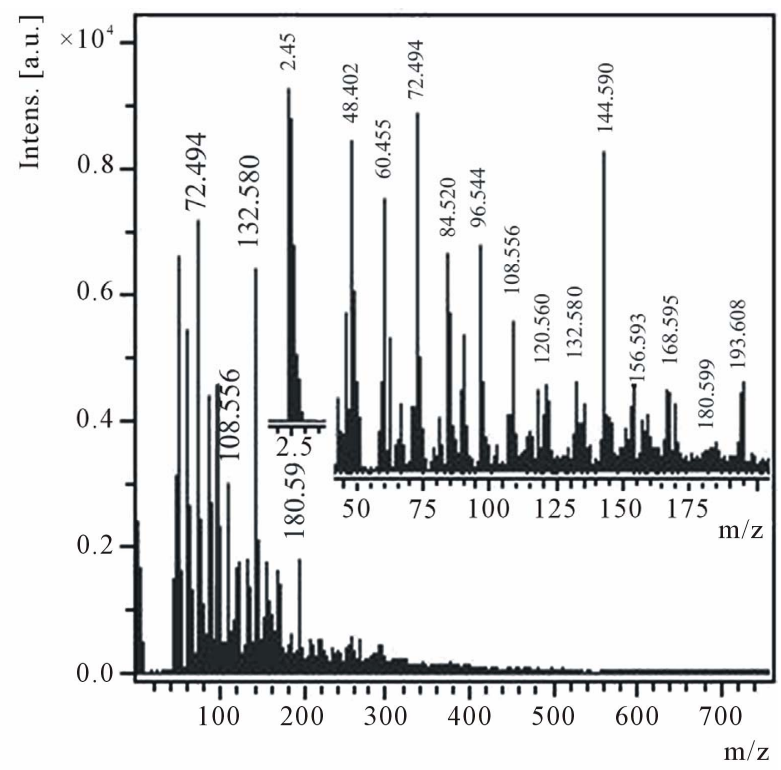

Figure 2. Anions mass spectrum of the ethanol solution of the product $B_{2}$ with $m / z 45-200$ and 2 - 4 regions in the insets.

laser irradiation of fullerene soot [35]. Probably, in fullerene soot formed at oligomerization of carbon clusters not only soluble in toluene $\mathrm{C}_{60}$ and $\mathrm{C}_{70}$ can be condensed as products by their increased clusterization. Precursors of $\mathrm{C}_{60}$ and $\mathrm{C}_{70}$ also can be condensed in this soot with formation of fixed (or otherwise deactivated) radicals (molecules), mainly soluble in alcohol and water.

In mass spectra of anions and cations of an extract $\mathbf{B}_{\mathbf{1}}$ there are groups of peaks with $\mathrm{m} / \mathrm{z} 720,696,672,648$ and 624 (Figure 3(a)), which, as it is accepted to consider, are characteristic for fullerene $\mathrm{C}_{60}$ and clusters $\mathrm{C}_{58}$,

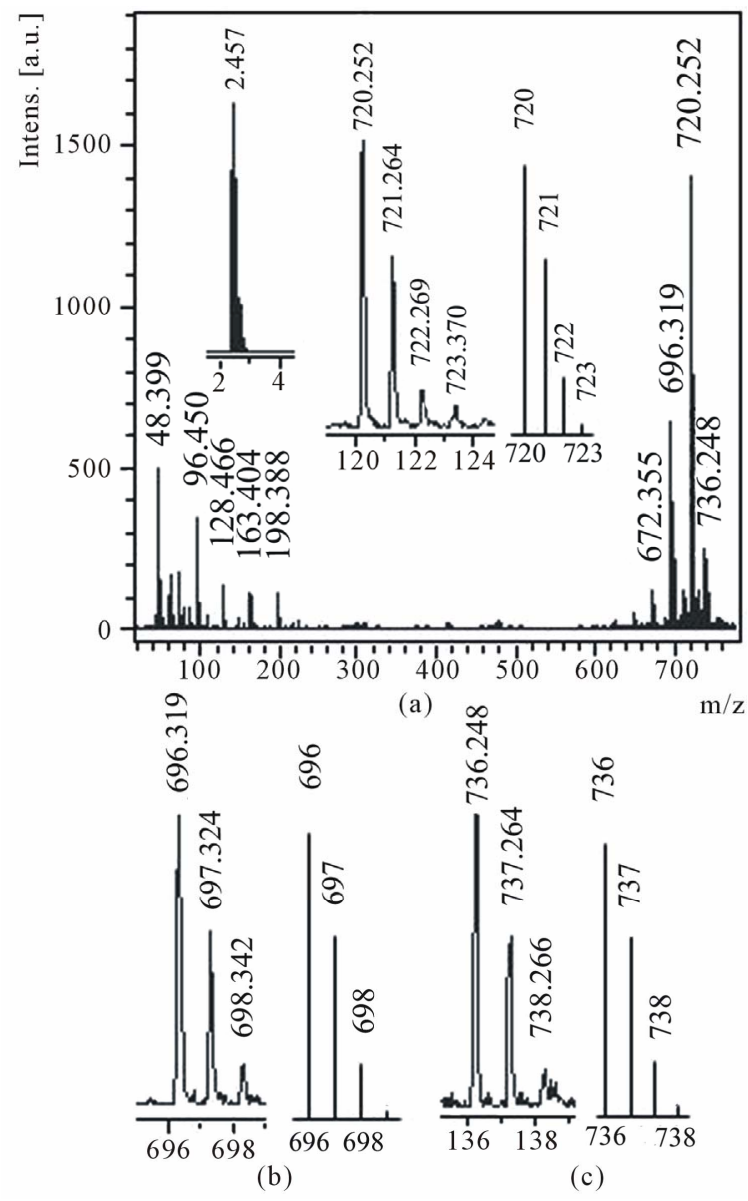

Figure 3. Anions mass spectrum of the toluene solution of the product $B_{1}$ (a) with the expansions of the experimental and theoretical isotope distributions for $\mathrm{C}_{60}$ in the inset, the expansions around the (b) $\mathrm{m} / \mathrm{z} 696$, (c) $\mathrm{m} / \mathrm{z} 736$ peaks and the calculated isotope mass ratios for $\mathrm{C}_{58}, \mathrm{C}_{60} \mathrm{H}_{16}$ molecules respectively.

$\mathrm{C}_{56}, \mathrm{C}_{54}$ and $\mathrm{C}_{52}$. Really, from thin structure of peaks $\mathrm{C}_{60}$ (Figure 3(a), inset), and $\mathrm{C}_{58}$ (Figure 3(b)) follows that the isotope distribution in these peaks completely corresponds to natural distribution of isotopes of carbon in molecules $\mathrm{C}_{60}$ and $\mathrm{C}_{58}$. In a spectrum of anions distinctly (against to a spectrum of cations) the periodicity in a range of peaks with $\mathrm{m} / \mathrm{z}$ from 48 up to 120 also is visible which was observed in mass spectra of negative ions of products soluble in water and ethanol. It is accepted to consider that clusters group closest on the size to $\mathrm{C}_{60}$ and group of smallest clusters are formed at destruction $\mathrm{C}_{60}$ or its derivatives ( $\left.\mathrm{La} @ \mathrm{C}_{60}, \mathrm{C}_{60} \mathrm{O}[36]\right)$ only at powerful laser irradiation. It is possible that substances soluble in water and ethanol are dissolved as well in toluene. Hydrogenated fullerenes $\mathrm{C}_{60} \mathrm{H}_{6}, \mathrm{C}_{60} \mathrm{H}_{16}$ and $\mathrm{C}_{60} \mathrm{H}_{20}$ which peaks distinctly are visible in spectra of both anions and cations are dissolved as well in toluene. According to thin structure of peak with $\mathrm{m} / \mathrm{z} 736$ (Figure 3(c)) the isotope distribution in it completely corresponds to cal- 
culated ratio of isotopes for a molecule $\mathrm{C}_{60} \mathrm{H}_{16}$.

\subsection{Products of Zone $C$}

Product C contains mainly transparent light particles. According to the data of the X-ray microanalysis (X-ray microanalyzer Camebax SX-50) the product consists only of carbon. The product $\mathbf{C}$ is practically completely dissolved in ethanol. Mass spectrum of anions (Figure 4) of an ethanol solution $\mathbf{C}_{\mathbf{1}}$ contains a group of the most intensive peaks with $\mathrm{m} / \mathrm{z} 36,48,60,72,84,96,108,120$, 132, 144 and 156, which can correspond to anions of small carbon molecules from $\mathrm{C}_{3}$ up to $\mathrm{C}_{13}$ (Figure 4, inset). Peaks with $\mathrm{m} / \mathrm{z} 169$ and 181, it is possible, correspond to hydrogenated molecules. According to thin structure of peak with $\mathrm{m} / \mathrm{z} 576$ isotope distributions in it correspond to a molecule $\mathrm{C}_{48}$.

Mass spectrum of cations (Figure 5) contains a group of peaks which the values $\mathrm{m} / \mathrm{z}(85,97,109,133$ and 193) can correspond to protonated molecules $\mathrm{C}_{7}, \mathrm{C}_{8}, \mathrm{C}_{9}, \mathrm{C}_{11}$ and $\mathrm{C}_{16}$ (Figure 5(b)). Three distinct peaks with $\mathrm{m} / \mathrm{z} 72$, 180 and 396 can correspond to molecules $C_{6}, C_{15}$ and $C_{33}$. Though, from thin structure of peak with $\mathrm{m} / \mathrm{z} 396$ (Figure 5(a), inset) follows that a part of molecules $\mathrm{C}_{33}$ are partially hydrogenated. Hence, the molecules $\mathrm{C}_{7}, \mathrm{C}_{8}$ and $\mathrm{C}_{9}$ are detected either as anions, or as protonated clusters. Only molecule $\mathrm{C}_{6}$ is detected in both spectra.

\subsection{Products of Zone D}

Soluble in toluene substances from a product D were extracted and deposited by ethanol. Deposited red-brown powder $\mathbf{D}_{1}$ was dissolved in acetone. Mass spectra of anions (Figure 6) and cations (Figure 7) of an acetone extract $\mathbf{D}_{\mathbf{1}}$ essentially differ. First of all, in a spectrum of anions a peak with $\mathrm{m} / \mathrm{z} 576$ is distinctly seen which, as is marked earlier, presents in mass spectrum of a product $\mathbf{C}_{\mathbf{1}}$ dissolved in ethanol. In a spectrum the peak with $\mathrm{m} / \mathrm{z}$ 576 is distinctly seen as well, the isotope distribution in which ((Figure 6(a), inset) differs from natural isotope distribution of carbon in a molecule $\mathrm{C}_{48}$. It is probably, molecule $\mathrm{C}_{48}$ is partially hydrogenated (up to $\mathrm{C}_{48} \mathrm{H}_{2}$ ). Hence, quasi-fullerene $\mathrm{C}_{48}$ is located in different zones of reactionary space and is easily dissolved both in ethanol and in acetone.

In a spectrum of anions (Figure 6(b)) there is a large group of very intensive peaks with relatively small values $\mathrm{m} / \mathrm{z}: 36,48,60,72,84,96,108,120,132,144,156,168$ and 180. Periodicity of occurrence of these peaks is 12 units that can demonstrate the belonging of these peaks to clusters from $C_{3}$ up to $C_{15}$. The similar structure of mass spectrum of anions was found out and for a product $\mathbf{C}_{\mathbf{1}}$ (Figure 4, inset), dissolved in ethanol. The very intensive peak with $\mathrm{m} / \mathrm{z} 255$ can correspond to hydrogenated molecule $\mathrm{C}_{21} \mathrm{H}_{3}$ (or $\mathrm{C}_{20} \mathrm{H}_{15}$ ). Just the peak with $\mathrm{m} / \mathrm{z} 255$

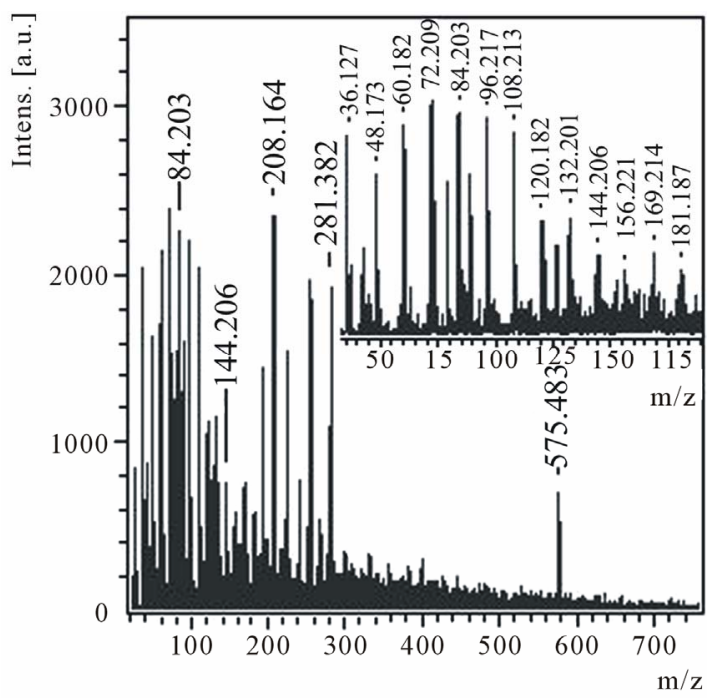

Figure 4. Anions mass spectrum of the ethanol solution of the product $C_{1}$ with $\mathrm{m} / \mathrm{z} 45$ - 185 region in the inset.

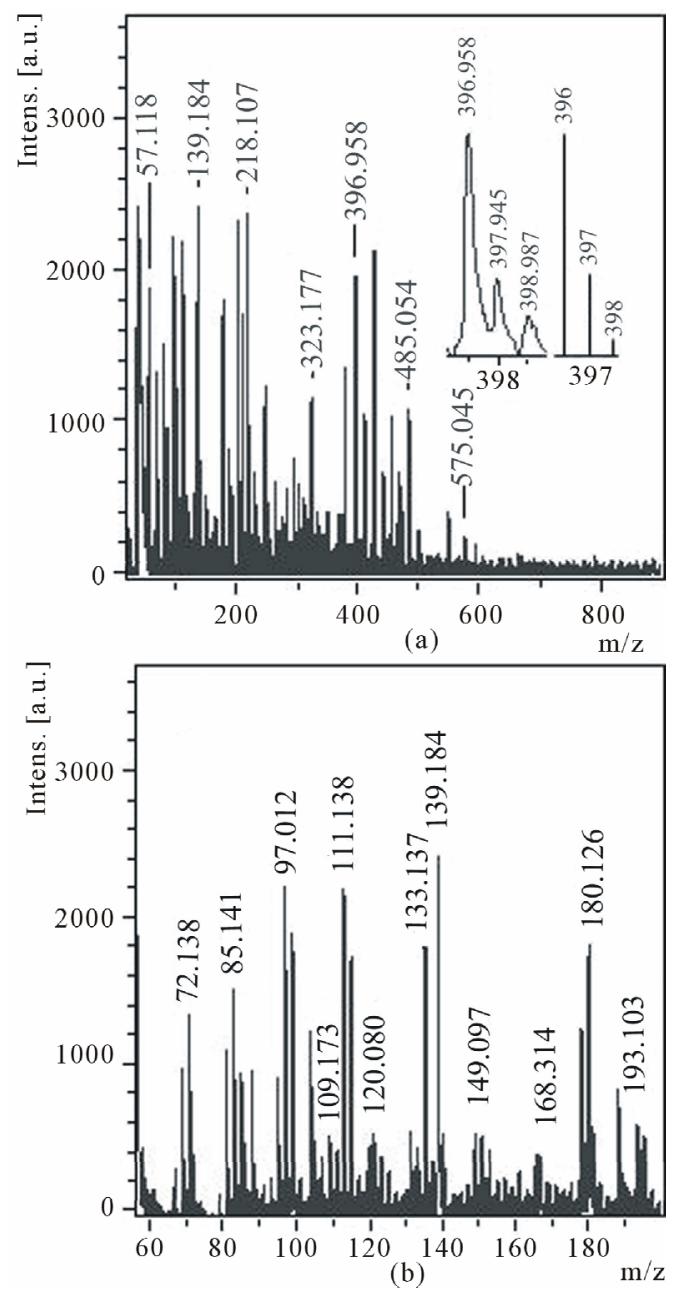

Figure 5. Cations mass spectrum of the ethanol solution of the product $C_{1}$ with the expansions of the experimental and theoretical isotope distributions for $C_{33}$ in the inset (a), $\mathbf{m} / \mathbf{z}$ 55 - 200 region (b). 

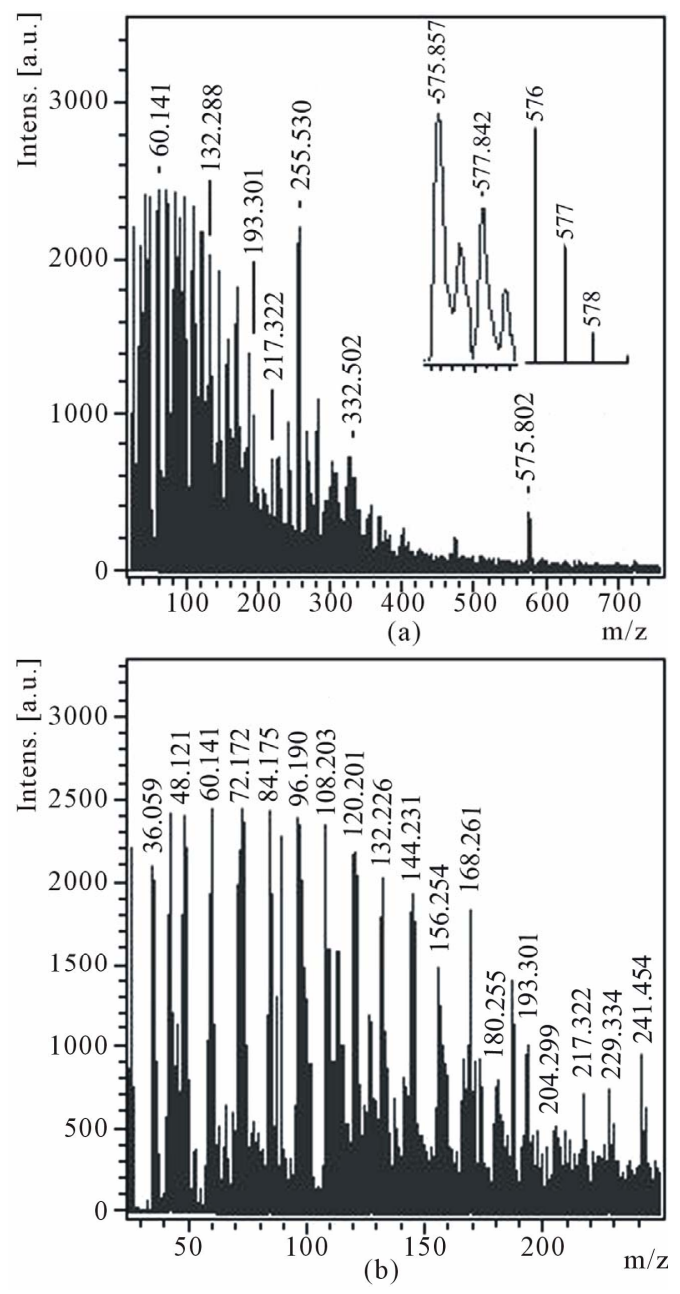

Figure 6. Anions mass spectrum of the acetone solution of the product $D_{1}$ with the expansions of the experimental and theoretical isotope distributions for $\mathrm{C}_{48}$ in the inset (a), $\mathrm{m} / \mathrm{z}$ 45 - 250 region (b).

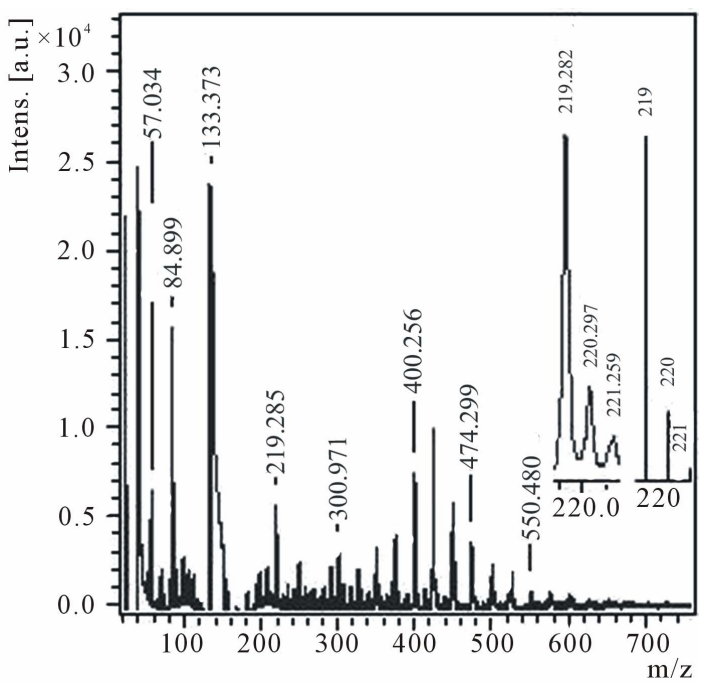

Figure 7. Cations mass spectrum of the acetone solution of the product $D_{1}$ with the expansion around the $m / z 219$. allows to see some difference in mass spectra of anions of products $\mathbf{C}_{\mathbf{1}}$ (transparent light particles) and $\mathbf{D}_{\mathbf{1}}$ (red brown powder). However, mass spectra of cations testify to essential distinctions of these products (Figure 5, Figure 7). In mass spectrum $\mathbf{D}_{\mathbf{1}}$ most intensive peak with $\mathrm{m} / \mathrm{z} 133$ as well as rather intensive peaks with $\mathrm{m} / \mathrm{z} 85$ and 219 is contained. It is possible to believe, that peaks with $\mathrm{m} / \mathrm{z} 85$ and 133 correspond to minimally hydrogenated molecules. The peak with $\mathrm{m} / \mathrm{z} 219$ can correspond also to protonated molecule $\mathrm{C}_{18} \mathrm{H}_{3}$ (Figure 7, inset). It is possible, that the product $\mathbf{D}_{1}$ contains stabilized by other products of benzene pyrolysis molecules $\mathrm{C}_{7}$ and $\mathrm{C}_{11}$, which are decomposed on clusters mainly of smaller size $\mathrm{C}_{3}-\mathrm{C}_{5}$ under laser beam.

Thus, clusters $\mathrm{C}_{3}-\mathrm{C}_{15}$ as well as $\mathrm{C}_{60}$ or $\mathrm{C}_{48}$ are detected as anions in all three products of benzene pyrolysis. In a spectrum of cations the molecules $\mathrm{C}_{6}-\mathrm{C}_{9}$ and $\mathrm{C}_{11}$ as well as $\mathrm{C}_{15}$ and $\mathrm{C}_{33}$ are detected only.

\subsection{Products $1 B$ of Zone B}

It is necessary to note that the composition of products of benzene pyrolysis, in particular, located in a zone B essentially depends on a regime of synthesis. From a product 1B obtained at lower temperature of pyrolysis were extracted by toluene the condensed substances and some of them deposited at addition of ethanol. The obtained deposit $\mathbf{2 B}$ as red (wax-similar) film was again dissolved in toluene and its mass spectra are submitted in Figure 8. Mass spectrum of anions (Figure 8(a)) contains the most intensive peak with $\mathrm{m} / \mathrm{z} 168$ as well as less intensive peaks with $\mathrm{m} / \mathrm{z}$ 96, 132 and 216 . From thin structure of peaks with $\mathrm{m} / \mathrm{z} 96$ and 168 follows, that the distribution of isotopes of carbon in them corresponds to molecules $\mathrm{C}_{8}$ and $\mathrm{C}_{14}$. At the same time, from the extended spectrum it is possible to see that some of small carbon molecules, for example $\mathrm{C}_{13}$, are hydrogenated essentially. The spectrum of cations (Figure 8(b)) testifies a high degree of hydrogenation of a product $\mathbf{2 B}$. The most intensive peak with $\mathrm{m} / \mathrm{z} 139$ according to its thin structure corresponds to a hydrogenated molecule $\mathrm{C}_{11} \mathrm{H}_{7}$. The peaks with the large values $\mathrm{m} / \mathrm{z}$ also correspond to hydrogenated molecules of carbon or thermostable polyaromatic hydrocarbons (PAHs) which can be intermediate at the formation $\mathrm{C}_{60}$ and its hydrides.

According to the chemical analysis a red product 2B consists of carbon, hydrogen (up to $4.2 \%$ mass.) and oxygen (up to $3.1 \%$ mass.). The composition of volatile products of thermal decomposition 2B was investigated by a method temperature-programmed desorbtion mass spectrometry (TPDMS). Thermodesorption measurement was carried out on monopole mass spectrometer MX7304A (Sumy, Ukraine) with impact electron ionization (EI) [37]. A sample 2B at the bottom of molibdeniumquarts ampoule was evacuated at room temperature up to 


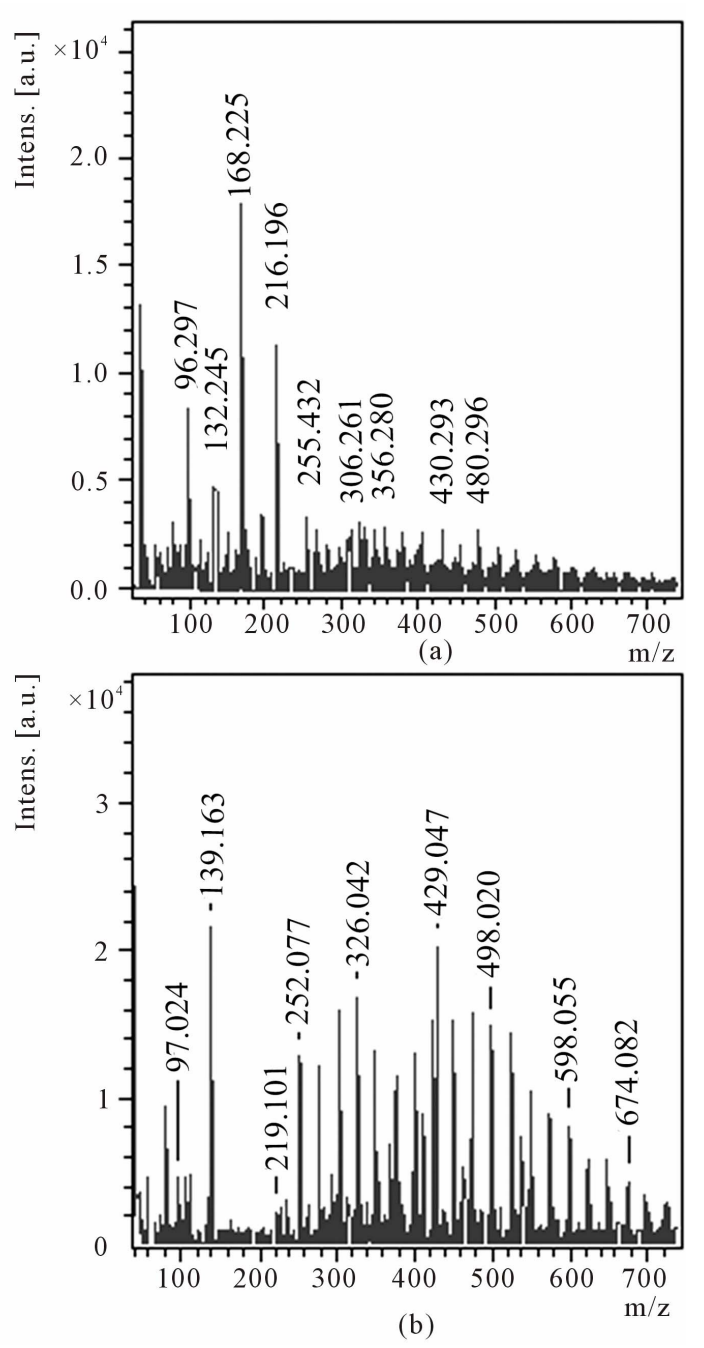

Figure 8. Anions (a) and cations (b) mass spectra of the toluene solution of the product $2 \mathrm{~B}$.

$5 \times 10^{-5} \mathrm{~Pa}$. The linear heating of a sample up to $650^{\circ} \mathrm{C}$ was carried out with speed $0.15 \mathrm{~K} \cdot \mathrm{s}^{-1}$ [37]. The volatile thermolysis products passed through a high-vacuum valve (5.4 $\mathrm{mm}$ in diameter) into the ionization chamber of the mass spectrometer The ion currents of the desorption and thermolysis products were recorded with a secondary-electron multiplier VEU-6. Mass spectra were Registered in a range 1 - $210 \mathrm{amu}$. The hydrogen as can see from a curve of thermodesorption (Figure 9(a)) begins allocation from a sample 2B already at room temperature (in vacuum) and in enough large amount. It is improbable that PAHs in a similar way can be decomposed. It should be noted that the intensive peaks of hydrogen is also observed in the MALDI mass spectra of water, ethanol and toluene solutions of the product $\mathbf{B}_{\mathbf{4}}$ (Figure 1, inset), $\mathbf{B}_{\mathbf{2}}$ (Figure 2, inset) and $\mathbf{B}_{\mathbf{1}}$ (Figure 3(a), inset) respectively. Mass spectrum EI at $200^{\circ} \mathrm{C}$ on Figure 9(b) is presented. Intensive peaks with 18, 28 and 44 amu correspond to molecular ions desorbed water, nitrogen and carbon dioxide, respectively. Ions with 31
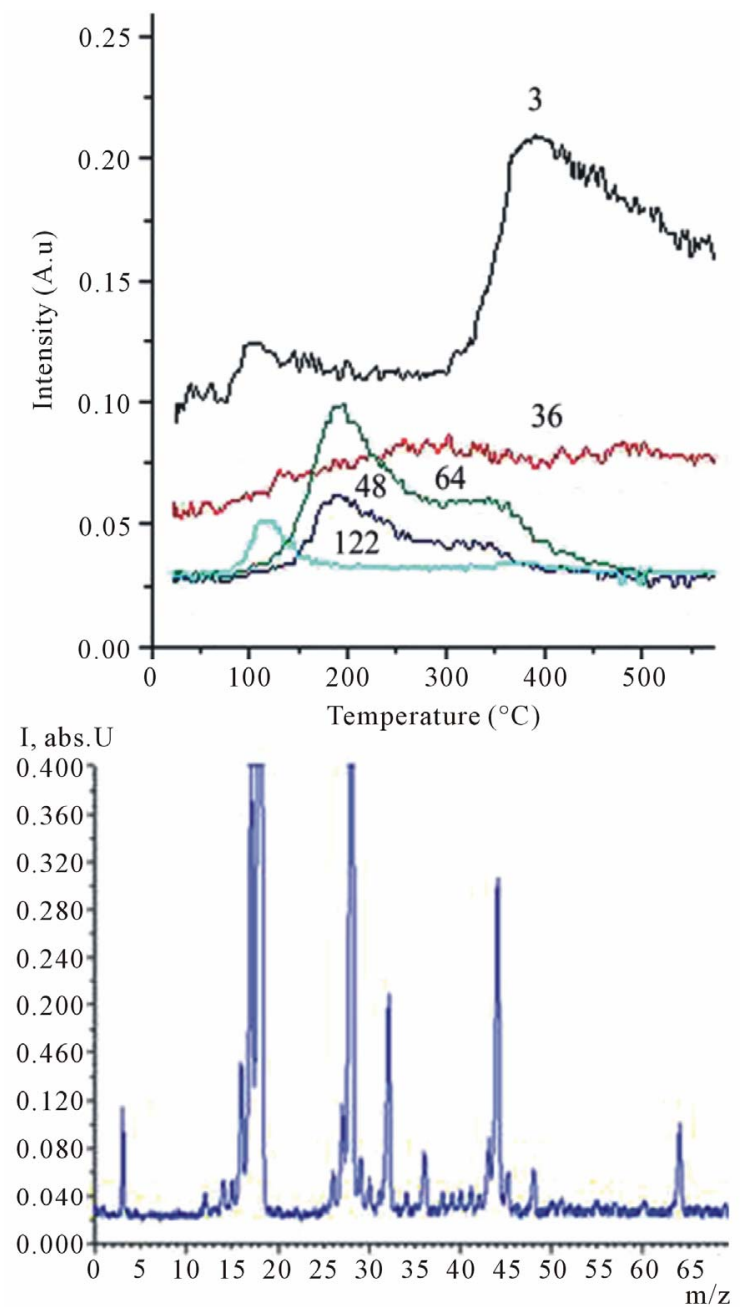

Figure 9. Experimental thermogram for selected $\mathrm{m} / \mathrm{z} 3,36$, 48, 64 and 122 peaks (a) and representative mass spectrum at $200^{\circ} \mathrm{C}$ (b) for the product $2 \mathrm{~B}$.

and $45 \mathrm{amu}$ as fragments of decomposition of molecules of the solvent (ethanol) are characteristic for EI mass spectra. The basic products of thermodesorption are carbon clusters $\mathrm{C}_{3}, \mathrm{C}_{4}$ and $\mathrm{C}_{5} \mathrm{H}_{2}$ with molecular mass 36,48 and 64 accordingly. It is possible that detected on MALDI mass spectra carboneous $\left(\mathrm{C}_{8}\right.$ and $\left.\mathrm{C}_{14}\right)$ and hydrogenated molecule $\left(\mathrm{C}_{11} \mathrm{H}_{7}\right)$ are thermo unstable already at low temperatures.

Thus, firstly clusters, distinctive for carbon plasma, are generated at destruction of substances obtained at hydrocarbon pyrolysis. Pyrolysis is carried out at temperatures excluding evaporation of carbon therefore small carbon clusters $\left(\mathrm{C}_{3}-\mathrm{C}_{5}\right)$ can be formed only due to dehydrogenation and destruction of benzene molecules. The destruction of a molecule $\mathrm{C}_{6} \mathrm{H}_{6}$ can be proceeded its complete dehydrogenation with formation of a linear or ring molecules $\mathrm{C}_{6}$ of polyynic or cumulenic structure. Clusters $\mathrm{C}_{7}-\mathrm{C}_{11}$ and $\mathrm{C}_{15}$ can be products of clusterization $\mathrm{C}_{3^{-}}$ $\mathrm{C}_{6}$. The formation of molecules $\mathrm{C}_{60}, \mathrm{C}_{48}$ and $\mathrm{C}_{33}$ can be 
realized owing to polycondensation of molecules $\mathrm{C}_{6} \mathrm{H}_{6}$, while hydrides $\left(\mathrm{C}_{60} \mathrm{H}_{6}, \mathrm{C}_{60} \mathrm{H}_{16}, \mathrm{C}_{60} \mathrm{H}_{20}\right)$ are formed because of reactions of polymerization of molecules $\mathrm{C}_{6} \mathrm{H}_{6}$ or hydrogenation of the formed molecules $\mathrm{C}_{60}$. It is possible, that the radicals, for example $\mathrm{C}_{6} \mathrm{H}_{5}$, are formed at partial dehydrogenation of molecules $\mathrm{C}_{6} \mathrm{H}_{6}$ which further, as well as $\mathrm{C}_{6}$, can be precursors of carbon molecules and clusters. However absence of biphenyl $\left(\mathrm{C}_{6} \mathrm{H}_{5}-\mathrm{C}_{6} \mathrm{H}_{5}\right)$ in products of benzene pyrolysis as product of the first stage of reaction of polycondensation $\mathrm{C}_{6} \mathrm{H}_{6}$, but presence of clusters $\mathrm{C}_{12}(\mathrm{~m} / \mathrm{z} 144)$ and $\mathrm{C}_{18}(\mathrm{~m} / \mathrm{z} 216)$ as dimer and trimer $\mathrm{C}_{6}$ accordingly, can testify to preferable formation $\mathrm{C}_{60}$ and $\mathrm{C}_{48}$ from carbon clusters, instead of from hydrocarbons radicals.

Very important question connected to the detailed mechanism of the formation $\mathrm{C}_{60}$ and $\mathrm{C}_{48}$, remains, open: whether clusters $\mathrm{C}_{6}$ of an initial molecule $\mathrm{C}_{6} \mathrm{H}_{6}$ accept participation in formation of molecules $\mathrm{C}_{60}$ and $\mathrm{C}_{48}$ ? Or these large carbon molecules are formed only due to increase of clusterization of fragments $\left(\mathrm{C}_{3}-\mathrm{C}_{5}\right)$ of disintergration $\mathrm{C}_{6}$ ?

Pyridine $\left(\mathrm{C}_{5} \mathrm{NH}_{5}\right)$ is heterocyclic analogue of benzene $\left(\mathrm{C}_{6} \mathrm{H}_{6}\right)$ therefore from precursors $\mathrm{C}_{5} \mathrm{~N}$ or $\mathrm{C}_{3}-\mathrm{C}_{5}$ should be formed accordingly heteroatomic or monoatomic fullerenes and quasi-fullerenes. Our preliminary researches $[29,30]$ have shown that at pyridine pyrolysis large nitrogen-carbon containing molecules are formed which further study represents not only scientific but also practical interest.

\section{Conclusion}

New method of organics pyrolysis for generation of carbon clusters as an alternative powerful laser (or arc-discharge) evaporation of graphite is developed. Condensation products obtained at new method of pyrolysis of benzene vapours by mass spectrometric method are studied. In products of all kinds of carbon molecules and some hydrides are detected. Obtained experimental results firstly demonstrate that the small carbon molecules can be generated in reactionary conditions excluding evaporation of carbon. The first stage of the transformation of benzene molecules to carbon molecules is their dehydrogenation and destruction. Firstly fullerene $\mathrm{C}_{60}$ and quasifullerenes $\mathrm{C}_{48}$ and $\mathrm{C}_{33}$ as well as small carbon molecules and some hydrides molecules in different substances are detected simultaneously.

\section{REFERENCES}

[1] H. W. Kroto, J. R. Heath, S. C. O'Brien, R. F. Curl and R. E. Smalley, "C $\mathrm{C}_{60}$ : Buckminsterfullerene," Nature, Vol. 318, No. 6042, 1985, pp. 162-163. doi:10.1038/318162a0

[2] E. A. Rohlfing, D. M. Cox and A. Kaldor, "Production and Characterization of Supersonic Carbon Cluster Beams,"
Chemical Physics, Vol. 81, No. 7, 1984, pp. 3322-3330. doi: $10.1063 / 1.447994$

[3] W. Kratschmer, L. D. Lamb, K. Fostiropoulos and D. R. Huffman, "Solid $\mathrm{C}_{60}$ : A New Form of Carbon," Nature, Vol. 347, No. 6291, 1990, pp. 354-358. doi: $10.1038 / 347354 \mathrm{a} 0$

[4] R. Taylor, J. P. Hare, A. K. Abdul-Sada and H. W. Kroto, "Isolation, Separation and Characterisation of the Fullerenes $\mathrm{C}_{60}$ and $\mathrm{C}_{70}$ : The Third Form of Carbon," Journal of the Chemical Society, Chemical Communications, Vol. 20, No. 20, 1990, pp. 1423-1425.

doi:10.1039/c39900001423

[5] F. Diederich, R. Ettl, Y. Rubin, R. L. Whetten, R. Beck, M. Alvarez, S. Anz, D. Sensharma, F. Wudl, K. C. Khemani and A. Koch, "The Higher Fullerenes: Isolation and Characterization of $\mathrm{C}_{76}, \mathrm{C}_{84}, \mathrm{C}_{90}, \mathrm{C}_{94}$, and $\mathrm{C}_{70} \mathrm{O}$, an Oxide of $\mathrm{D}_{5 \mathrm{~h}}-\mathrm{C}_{70}$," Science, Vol. 252, No. 5005, 1991, pp. 548551. doi:10.1126/science.252.5005.548

[6] F. Diederich, R. L. Whetten, C. Thilgen, R. Ettl, I. Chao and M. M. Alvarez, "Fullerene Isomerism: Isolation of $\mathrm{C}_{2 v},-\mathrm{C}_{78}$ and $\mathrm{D}_{3}-\mathrm{C}_{78}$," Science, Vol. 254, No. 5039, 1991, pp. 1768-1770. doi:10.1126/science.254.5039.1768

[7] M. D. Diener and J. M. Alford, "Isolation and Properties of Small-Bandgap Fullerenes," Nature, Vol. 393, No. 6686, 1998, pp. 668-671. doi:10.1038/31435

[8] Ph. Gerhardt, S. Löffler and K. H. Homann, "Polyhedral Carbon Ions in Hydrocarbon Flames," Chemical Physics Letters, Vol. 137, No. 4, 1987, pp. 306-310. doi:10.1016/0009-2614(87)80889-8

[9] J. B. Howard, J. T. McKinnon, Y. Makarovsky, A. L. Lafleur and M. E. Johnson, "Fullerenes $\mathrm{C}_{60}$ and $\mathrm{C}_{70}$ in Flames," Nature, Vol. 352, No. 6331, 1991, pp. 139-141. doi: $10.1038 / 352139 \mathrm{a} 0$

[10] G. M. Jenkins, L. R. Holland, H. Maleki and J. Fisher, "Continuous Production of Fullerenes by Pyrolysis of Acetylene at a Glassy Carbon Surface," Carbon, Vol. 36, No, 12, 1998, pp. 1725-1727. doi:10.1016/S0008-6223(97)00220-0

[11] R. Taylor, G. J. Langley, H. W. Kroto and D. R. M. Walton, "Formation of $\mathrm{C}_{60}$ by Pyrolysis of Naphthalene," Nature, Vol. 366, No. 6457, 1993, pp. 728-731. doi: $10.1038 / 366728 \mathrm{a} 0$

[12] C. J. Crowley, R. Taylor, H. W. Kroto, D. R. M. Walton, P. C. Cheng and L. T. Scott, "Pyrolytic Production of Fullerenes," Synthetic Metals, Vol. 77, No. 1-3, 1996, pp. 17-22. doi:10.1016/0379-6779(96)80048-8

[13] J. Osterodt, A. Zett and F. Vögtle, "Fullerenes by Pyrolysis of Hydrocarbons and Synthesis of Isomeric Methanofullerenes," Tetrahedron, Vol. 52, No. 14, 1996, pp. 49494962. doi:10.1016/0040-4020(96)00103-2

[14] C. Piskoti, J. Yarger and A. Zettl, "A New Carbon Solid,

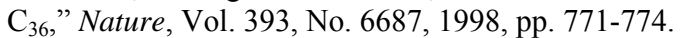
doi: $10.1038 / 31668$

[15] A. Koshio, M. Inakuma, T. Sugai and H. Shinohara, "A Preparative Scale Synthesis of $\mathrm{C}_{36}$ by High Temperature Laser Vaporization: Purification and Identification of $\mathrm{C}_{36} \mathrm{H}_{6}$ and $\mathrm{C}_{36} \mathrm{H}_{6} \mathrm{O}$," Journal of the American Chemical Society, Vol. 122, No. 2, 2000, pp. 398-399. 
doi:10.1021/ja9934347

[16] Z. Wang, X. Ke, Z. Zhu, F. Zhu, M. Ruan, H. Chen, R. Huang and L. Zheng, "A New Carbon Solid Made of the World's Smallest Caged Fullerene $\mathrm{C}_{20}$," Physics Letters A, Vol. 280, No. 5-6, 2001, pp. 351-356. doi:10.1016/S0375-9601(00)00847-1

[17] Z. Iqbal, Y. Zhang, H. Grebel, S. Vijayalakshmi, A. Lahamer, G. Benedek, M. Bernasconi, J. Cariboni, I. Spagnolatti, R. Sharma, F. J. Owens, M. E. Kozlov, K. V. Rao and M. Muhammed, "Evidence for a Solid Phase of Dodecahedral $\mathrm{C}_{20}$," European Physical Journal B, Vol. 31, No. 4, 2003, 509-515. doi:10.1140/epjb/e2003-00060-4

[18] T. Guo, M. D. Diener, Y. Chai, M. J. Alford, R. E. Haufler, S. M. McClure, T. Ohno, J. H. Weaver, G. E. Scuseria and R. E. Smalley, "Uranium Stabilization of $\mathrm{C}_{28}$ : A Tetravalent Fullerene," Science, Vol. 257, No. 5077, 1992, pp. 1661-1664. doi:10.1126/science.257.5077.1661

[19] Z. Chen, "The Smaller Fullerene $\mathrm{C}_{50}$, Isolated as $\mathrm{C}_{50} \mathrm{Cl}_{10}$," Angewandte Chemie International Edition, Vol. 43, No. 36, 2004, pp. 4690-4691. doi:10.1002/anie.200401764

[20] F. Cataldo, "Cyanopolyynes: Carbon Chains Formation in a Carbon Arc Mimicking the Formation of Carbon Chains in the Circumstellar Medium," International Journal of Astrobiology, Vol. 3, No. 03, 2004, pp. 237-246. doi: $10.1017 /$ S1473550404002149

[21] F. Cataldo, "Simple Generation and Detection of Polynes in an Arc Discharge between Graphite Electrodes Submerged in Various Solvents," Carbon, Vol. 41, No. 13, 2003, pp. 2653-2689. doi:10.1016/S0008-6223(03)00345-2

[22] F. Cataldo, "Synthesis of Polyynes in a Submerged Electric Arc in Organic Solvents," Carbon, Vol. 42, No. 1, 2004, pp. 129-142. doi:10.1016/j.carbon.2003.10.016

[23] W. Jr. Weltner, P. N. Walsh and C. L. Angell, "Spectroscopy of Carbon Vapor Condensed in Rare-Gas Matrices at $4^{\circ}$ and $20^{\circ} \mathrm{K}$. I," Journal of Chemical Physics, Vol. 40, 1964, pp. 1299-1305. doi:10.1063/1.1725312

[24] I. Cermak, M. Förderer, S. Kalhofer, H. Stopka-Ebeler and W. Krätschmer, "Laser-Induced Emission Spectroscopy of Matrix-Isolated Carbon Molecules: Experimental Setup and New Results on $\mathrm{C}_{3}$," Journal of Chemical Physics, Vol. 108, No. 24, 1998, pp. 10129-10142. doi: $10.1063 / 1.476472$

[25] A. I. Kharlamov, S. V. Loythenko, N. V. Kirillova, S. V. Kaverina and V. V. Fomenko, "Toroidal Nanostructures of Carbon. Single-Walled 4-, 5- and 6-Hadrons and Nanorings," Reports of the National Academy of Sciences of Ukraine, No. 1, 2004, pp. 95-100.

https://www.etde.org/etdeweb/details_open.jsp?osti_id=2 0465861

[26] A. I. Kharlamov, L. N. Ushkalov, N. V. Kirillova, V. V. Fomenko and N. I. Gubareny, "Synthesis of Onion Nanostructures of Carbon at Pyrolysis of Aromatic Hydrocarbons," Reports of the National Academy of Sciences of Ukraine, No. 3, 2006, pp. 97-103.

[27] G. Kharlamova, A. Kharlamov, N. Kirillova and A. Skripnichenko, "Novel Transparent Molecular Crystals of Carbon," In: A. Vaseashta and I. Mihailescu, Eds., Func- tionalized Nanoscale Materials, Devices and Systems, Springer, Dordrecht, 2008, pp. 373-379. doi:10.1007/978-1-4020-8903-9 34

[28] A. I. Kharlamov and N. V. Kirillova, "Fullerenes and Hydrides of Fullerenes as Products Transformation (Polycondensation) of Molecules of Aromatic Hydrocarbons," Reports of the National Academy of Sciences of Ukraine, No. 5, 2009, pp. 110-118.

http://www.nbuv.gov.ua/portal/all/reports/2009-05/09-0519.html

[29] A. Kharlamov, G. Kharlamova, O. Khyzhun and N. Kirillova, "New Substances: Red Carbon Suboxide, Red N-Doped Fullerene $\left(\mathrm{C}_{50} \mathrm{~N}_{10}\right) \mathrm{O}_{3} \mathrm{H}_{10}$ and Red Carbon," In: S. Zaginaichenko, D. Schur, V. Skorokhod, Eds., Carbon Nanomaterials in Clean-Energy Hydrogen Systems, Springer, Dordrecht, 2011, pp. 257-268. doi:10.1007/978-94-007-0899-0 24

[30] O. Kharlamov, G. Kharlamova, N. Kirillova, O. Khyzhun and V. Trachevskii, "Synthesis of New Carbon Compounds: N-Doped Fullerene $\left(\mathrm{C}_{50} \mathrm{~N}_{10}\right) \mathrm{O}_{3} \mathrm{H}_{10}$ and 'Pyridine' Nanocarbon," In: A. Vaseashta, E. Braman and P. Susmann, Eds., Technological Innovations in Sensing and Detection of Chemical, Biological, Radiological, Nuclear Threats and Ecological Terrorism, Springer, Dordrecht, 2012, pp. 245-253. doi:10.1007/978-94-007-2488-4 27

[31] A. I. Kharlamov, M. E. Bondarenko and N. V. Kirillova, "New Method for Synthesis of Fullerenes and Fullerene Hydrides from Benzene," Russian Journal of Applied Chemistry, Vol. 85, No. 2, 2012, pp. 233-239. doi:10.1134/S1070427212020127

[32] R. F. C. Brown, "Pyrolytic Methods in Organic Chemistry: Application of Flow and Flash Vacuum Pyrolytic Techniques," Academic Press, New York, 1980.

[33] M. J. Plater, M. Praveen and D. M. Schmidt, "Buckybowlsynthesis: A Novel Application of Flash Vacuum Pyrolysis," Fullerene Science and Technology, Vol. 5, No. 4, 1997, pp. 781-800. doi:10.1080/15363839708012231

[34] N. R. Conley and J. J. Lagowski, "On an Improved Pyrolytic Synthesis of [60]- and [70]-Fullerene," Carbon, Vol. 40 , No. 6, 2002, pp. 949-953. doi:10.1016/S0008-6223(01)00227-5

[35] M. A. Khodorkovsky, T. O. Artamonova, S. V. Murashov A. L. Shahmin, A. A. Belyaeva, L. P. Rakcheeva, I. M. Fonseca and S. B. Lubchik, "The Study of the Higher Fullerenes by Ablation of Carbonaceous Materials," Technical Physics, Vol. 75, No. 10, 2005, pp. 51-54. http://www.ioffe.rssi.ru/journals/jtf/2005/10/p51-54.pdf

[36] Q. Kong, L. Zhao, J. Zhuang, J. Xu, S. Qian, Y. Li, R. Cai, H. Hou and J. Wang, "Formation of Odd-Numbered Fullerene-Related Species and Its Relation to the Formation of Metallofullerenes," International Journal of Mass Spectrometry, Vol. 209, No. 1, 2001, pp. 69-79. doi:10.1016/S1387-3806(01)00477-8

[37] T. V. Kulik, V. N. Barvinchenko, B. B. Palyanitsa, O. V. Smirnova, V. K. Pogorelyi and A. A. Chuiko, "A Desorption Mass Spectrometry Study of the Interaction of Cinnamic Acid with a Silica Surface," Russian Journal of Physical Chemistry A, Vol. 81, No. 1, 2007, pp. 83-90. doi:10.1134/S0036024407010165 